\title{
Oxidation of Fish Oil Oleogels Formed by Natural Waxes in Comparison With Bulk Oil
}

\author{
Hong-Sik Hwang,* Matthew Fhaner, Jill K. Winkler-Moser, and Sean X. Liu
}

The aim of this study is to evaluate the oleogel (or organogel) technology as a new method to prevent oxidation of fish oil by immobilizing oil and to provide useful information on oxidation of oleogels for their application in actual food products. Four different natural waxes, rice bran wax, sunflower wax, candelilla wax, and beeswax are used to prepare fish oil oleogels. Peroxide value, conjugated diene value, eicosapentaenoic acid (EPA), and docosahexaenoic acid (DHA) are measured after storing oleogels at 35 and $50^{\circ} \mathrm{C}$, respectively. All $3 \%$ wax-fish oil oleogels shows slower oxidation than the bulk fish oil at $35^{\circ} \mathrm{C}$. Beeswax is not as effective as other waxes during storage at $50^{\circ} \mathrm{C}$ due to its lower melting point. The color penetration measurement method is developed as a convenient method to predict the oxidation rate of oleogel. Cooling oleogel at a faster rate can significantly reduce the oxidation rate of the oleogel. A larger amount of wax is not recommended to increase the protective effect, which can give a negative effect due to the prooxidant activity of wax. The oleogel technology may be applied to reduce oxidation of food products and nutritional supplements containing omega-3 oil.

Practical Application: This study clearly shows that the oleogel technology can be used to prevent oil oxidation by immobilizing oil in food products. This technology can be used for commercial products such as fish oil supplements to prevent oil oxidation during production, transportation, and storage. The information presented in this study can also be used for new omega-3 oil fortified food products such as margarine, spreads, shortening, cookies, and other related products. The oleogel technology can be easily applied as a dropin method. Natural waxes used as oleogelator are inexpensive and widely available, and most of them are already used in many food products.

\section{Introduction}

Hydrogenated vegetable oils have widely been used to provide desired texture to an oil-based food product such as

Dr. H.-S. Hwang, Dr. J. K. Winkler-Moser, Dr. S. X. Liu

United States Department of Agriculture

Agricultural Research Service

National Center for Agricultural Utilization Research

Functional Foods Research

Peoria, IL, USA

E-mail: hongsik.hwang@ars.usda.gov

Prof. M. Fhaner

Department of Chemistry and Biochemistry

University of Michigan-flint

Flint, MI, USA

DOI: 10.1002/ejlt.201700378 margarine, spreads and shortening. However, trans fats that are produced during the hydrogenation process have negative effects on several diseases such as cardiovascular disease, diabetes and some types of cancers. ${ }^{[1-3]}$ For this reason, many countries and municipalities implemented regulations to reduce or eliminate trans fats in foods. In turn, tropical oils such as palm oil and coconut oil along with fully hydrogenated vegetable oils and their transesterified oils have become the most popular alternatives to trans fats in the food industry. However, it should be noted that these oils contain high contents of saturated fats and could also cause some health problems such as the increased risk of cardiovascular disease (CVD) and increased LDL cholesterol levels. ${ }^{[4]}$

An oleogel or organogel is a class of gel made of an oil immobilized by a threedimensional network formed by an oleogelator. Structuring edible oil with an oleogelator has become an important research area to replace harmful fats such as trans and saturated fats. In an oleogel, oil is mixed with an edible oleogelator, heated, and cooled to form a gel. Although there are many kinds of oleogelators developed, plant waxes such as rice bran wax (RBW), sunflower wax (SW), candelilla wax (CW), and beeswax (BW) have many advantages over other oleogelators due to their availability, low cost, and great gelling ability. ${ }^{[5]}$ Oleogels can be made from many different vegetable oils including canola, soybean, flaxseed, olive, peanut, sesame, walnut, and corn oils. ${ }^{[6]}$ Omega-3 oils including fish oil have a multitude of health benefits such as brain development in fetuses, reduction of inflammation, and reduction in the incidence of heart attacks. ${ }^{[7-9]}$ Therefore, consumption of omega-3 oil supplements and foods fortified with omega-3 oils such as cereals, breads, yogurt, milk, and breakfast and snack bars have increased in recent years. ${ }^{[10,11]}$ Oleogels of fish oil are considered to be excellent alternatives to saturated fats in margarine, spreads, and shortening. ${ }^{[12-14]}$ One challenge in manufacturing, storing, and transporting of omega-3 oil containing foods and supplements is that polyunsaturated fatty acids (PUFAs) in omega-3 oils are readily oxidized. ${ }^{[15]}$ As an example, Ogutcu et al. ${ }^{[12]}$ reported that fish oil oleogels showed 
faster oxidation than commercial margarine. The oxidation of PUFAs causes negative impacts on nutrition, flavor, and odor of the food product. ${ }^{[16,17]}$

Understanding the oxidation of oleogels is critical for the development of a variety of healthy food products using the oleogel technology. The goal of this study was to conduct a systematic study on oxidation of fish oil oleogels formed by natural waxes. If the oleogel technology could effectively protect fish oil from oxidation, it could be used as a new method to prevent oil oxidation during production, transportation, and storage of fish oil supplements, which has always been challenging in this industry. There have been a few studies on the oxidation of oleogels. For example, cod liver oil gelled with monoglyceride showed a slower formation of secondary oxidation products than bulk oil while it showed no difference in the formation of PV. ${ }^{[18]}$ There were some studies on wax-oleogels as well, which provided valuable information on oleogel properties including oxidative stability. However, in most studies, peroxide value (PV) was the only analytical method used to measure the oxidative stability of oleogel. ${ }^{[12,14,19,20]}$ It is well known that any single analytical method measuring only one kind of oxidation product cannot give a satisfactory description of lipid oxidation throughout the entire course of oxidation since there are numerous oxidation products. ${ }^{[21,22]}$ Furthermore, it is not very clear yet that gelling oil can reduce oil oxidation since there are some contradictory findings regarding the oxidation rate of oleogel compared to that of bulk oil. ${ }^{[12,13]}$ Therefore, more systematic studies are needed for better understanding of oleogel oxidation. In this study, we measured PV for the evaluation of oil oxidation at the early stage of oxidation and determined conjugated diene value (CDV), eicosapentaenoic acid (EPA), and docosahexaenoic acid (DHA) for a longer storage time. We also examined the effects of different natural waxes, the wax amount, and the cooling rate during gelling along with the possible prooxidant activity of wax. For these purposes, fish oil organogel samples were prepared with four different natural waxes, with different amounts of wax, and by different cooling rates and their oxidative stabilities were compared.

\section{Experimental Section}

\subsection{Materials}

Commercial fish oil was purchased from Nordic Naturals (Watsonville, CA, USA). Rice bran wax (RBW), sunflower wax $(\mathrm{SW})$, candelilla wax $(\mathrm{CW})$, and beeswax $(\mathrm{BW})$ were obtained from Glenn Corporation (Lake Elmo, MN), TKB Trading (Oakland, CA), Sigma-Aldrich (St. Louise, MO), and Koster Keunen Inc. (Watertown, CT), respectively. Fatty acid methyl ester (FAME) standards were purchased from Nu-Chek Prep (Elysian, MN, USA). Ammonium thiocyanate, barium chloride, iron(II) sulfate heptahydrate, 2,2,4-trimethylpentane (isooctane), and Sudan III were purchased from Sigma-Aldrich (St. Louis, MS, USA). Deuterated chloroform $\left(\mathrm{CDCl}_{3}\right)$ was purchased from Cambridge Isotope Laboratories, Inc. (Andover, MA). HPLC- grade solvents including chloroform, methanol, and hexane were purchased from Fisher Scientific (Fair Lawn, NJ, USA).

\subsection{Preparation of Oleogels and Storage Study}

For $3 \%$ wax oleogels, $90 \pm 2 \mathrm{mg}$ wax was weighed in a glass vial (15 mm O.D. $\times 45 \mathrm{~mm}$ height, $12.7 \mathrm{~mm}$ I.D.). While lightly blowing argon into the fish oil bottle, fish oil (2.91 g) was weighed into the vial. The calculated ratio of surface area to volume was $0.39 \mathrm{~cm}^{2} \mathrm{~cm}^{3}$ by this method. Samples were put in a $100^{\circ} \mathrm{C}$ oven for exactly $7 \mathrm{~min}$ and were shaken to mix molten wax and fish oil and then cooled at room temperature. The control, bulk fish oil without wax, was also subjected to this procedure to have equal oxidation during this step. Using an extra oleogel sample in a vial, the cooling rate was measured by putting a wire probe at the center of the sample. Since the cooling curve was not linear, time taken from 70 to $40^{\circ} \mathrm{C}$, in which crystallization of wax occurred, was used to determine the cooling rate. The cooling rate by this method was determined to be $5.3 \pm 0.4{ }^{\circ} \mathrm{C} \mathrm{min}^{-1}$ (cooling rate 1). Using a Q-tip, the extra gel formed above the top line of the oleogel was wiped off. Samples were stored in ovens at 35 and $50^{\circ} \mathrm{C}$ to simulate possible excessive heat during transportation and manufacturing, respectively. A set of samples were subjected to $90^{\circ} \mathrm{C}$ to investigate the effect of molten wax on oxidation of fish oil without the gelling effect. Samples with different cooling rates were prepared in the same way except for the cooling method. One set of samples were cooled in a freezer $\left(-20^{\circ} \mathrm{C}\right)$ by placing the sample vials in the freezer, of which the cooling rate was measured at $11.0 \pm 0.1$ (cooling rate 2). The other set of samples were cooled by immersing the sample vial in an ice bath, for which the cooling rate was determined to be $25.3 \pm 1.5^{\circ} \mathrm{C} \mathrm{min}^{-1}$ (cooling rate 3 ). Oleogels with different amounts of wax were prepared under the same conditions except for using the cooling method for the cooling rate 1 . For oleogels, the most oxidation might have occurred on the surface. To evenly distribute oxidized oil in the vial, samples were heated in the $100^{\circ} \mathrm{C}$ oven for $4 \mathrm{~min}$, shaken vigorously, and cooled down to room temperature. Although this procedure further oxidized samples, we found this method the most effective to mix the sample. The control, bulk fish oil without wax, was also subjected to this heating and mixing procedure to oxidize under the same conditions. Samples were stored in the freezer $\left(-20^{\circ} \mathrm{C}\right)$ until analyses. Three replicates were used for each sample. Since heat was involved in the preparation of oleogels to dissolve wax in oil, it was necessary to confirm that heat did not cause any difference in the oxidation status of initial oleogel samples, especially, for oleogels with different waxes due to the possible prooxidant activity of wax. For this, 0-hr samples were prepared and analyzed separately in each set of experiments. It was confirmed that there was no significant difference in oxidation statuses of 0-hr samples.

\subsection{Peroxide Value (PV)}

Peroxide value (PV) was determined using a modified International Dairy Federation (IDF) standard method. ${ }^{[23]}$ In 
this method the concentration of ferric $\left(\mathrm{Fe}^{3+}\right)$ ions was determined, which were formed by the oxidation of ferrous $\left(\mathrm{Fe}^{2+}\right)$ ions via peroxides. Therefore, the standard curve of the absorbance at $510 \mathrm{~nm}$ versus different ferric $\left(\mathrm{Fe}^{3+}\right)$ iron concentrations was prepared with $1-15 \mu \mathrm{g} \mathrm{Fe}{ }^{3+} / \mathrm{ml}$ in 7:3 chloroform/methanol using a UV/Vis spectrophotometer, PerkinElmer Lambda 35 (Perkin Elmer, Waltham, MA, USA). A ferrous chloride solution was prepared in advance by slowly adding barium chloride solution $(0.2 \mathrm{~g}$ in $25 \mathrm{ml}$ DI water) to a ferrous sulfate solution $\left(0.25 \mathrm{~g} \mathrm{FeSO}_{4}-7 \mathrm{H}_{2} \mathrm{O}\right.$ in $25 \mathrm{ml} \mathrm{DI}$ water), and adding $1 \mathrm{ml}$ of $10 \mathrm{~N} \mathrm{HCl}$ while stirring. Oleogel samples (approximately $10 \mathrm{mg}$ ) were weighed into test tubes (Pyrex, $16 \times 150 \mathrm{~mm})$ and diluted with chloroform/methanol (7:3, $9.8 \mathrm{ml})$. Ammonium thiocyanate $\left(50 \mu \mathrm{l}, 0.3 \mathrm{~g} \mathrm{ml}^{-1}\right)$ was added to the test tube and vortexed for $10-15 \mathrm{~s}$. The ferrous chloride solution was then added to the test tube containing the sample and vortexed for 10-15 s. The sample was allowed to rest for 5 min in subdued light, then transferred to quartz cuvettes, and the absorbance of each solution was measured at $510 \mathrm{~nm}$ in the UV/Vis spectrophotometer. Samples were analyzed in duplicate. The PV was calculated using the following equation:

$P V=\frac{(A s-A b) \times m}{55.84 \times m_{\mathrm{o}} \times 2}$

$A_{s}$ : The absorbance of the sample, $A_{b}$ : The absorbance of the blank, $m$ : The slope of the standard curve, $m_{o}$ : Mass of the sample.

\subsection{Conjugated Diene Value (CDV)}

Conjugated diene value (CDV) was measured using the AOCS official method Ti 1a-64. ${ }^{[2]}$ In brief, oleogel (approximately $10 \mathrm{mg}$ ) was weighed into a test tube (Pyrex, $16 \times 125 \mathrm{~mm}$ ), isooctane $(10 \mathrm{ml})$ was added to the test tube, the solution was allowed to rest for 10-15 min, $1.0 \mathrm{ml}$ of solution was removed to a new test tube and diluted with isooctane $(9 \mathrm{ml})$. The solution was transferred into a quartz cuvette and the absorbance was measured with a PerkinElmer Lambda 35 (Perkin Elmer, Waltham, MA, USA) UV/Vis spectrophotometer at $233 \mathrm{~nm} \cdot{ }^{[25]}$ Samples were analyzed in duplicate. The CDV was determined using the following equation:

$C D V=0.84 \times\left[\left(\frac{A_{\mathrm{s}}}{b \times c}\right)-k_{\mathrm{o}}\right]$

$K_{o}$ : Absorptivity by acid or ester groups, $A_{s}$ : Observed absorbance at $233 \mathrm{~nm}$ of the sample, $b$ : Cuvette length in $\mathrm{cm}, c$ : Concentration of the sample in $\mathrm{g} \mathrm{L}^{-1}$.

\subsection{EPA and DHA Analyses}

Levels of the major fatty acids in fish oil, eicosapentaenoic acid (EPA) and docosahexaenoic acid (DHA) were determined by converting oil to the fatty acid methyl ester (FAME) followed by fatty acid analysis with gas chromatography (GC). ${ }^{[26,27]}$ Briefly, the oleogel sample (about $10 \mathrm{mg}$ ) was dissolved in hexane
$(1.4 \mathrm{ml})$, methanolic $\mathrm{KOH}(2 \mathrm{~N}, 200 \mu \mathrm{l})$ was added, and the solution was vortexed for $2 \mathrm{~min}$. After resting for $1 \mathrm{~min}$, the hexane portion was transferred to an autosampler vial. Analysis of FAME concentrations was conducted with an Agilent 6890 GC (Palo Alto, CA, USA) equipped with a Supelco SP-2380 capillary column (Bellefonte, PA, USA, $30 \times 0.25 \mathrm{~mm}$ ID $\times 0.20 \mu \mathrm{m}$ film). The GC conditions employed were as follows: Flow rate $1 \mathrm{ml} \mathrm{min}^{-1}$ (Helium), injector temperature $220^{\circ} \mathrm{C}$, oven temperature $185^{\circ} \mathrm{C}$, split ratio 50:1, and FID temperature $220^{\circ} \mathrm{C}$. Peaks were identified with commercial FAME standards. The relative area ratios (\%) of EPA and DHA to the sum of the areas of all the fatty acid peaks are reported. Samples were analyzed in duplicate.

\subsection{Differential Scanning Calorimetry (DSC)}

DSC experiments were performed on a TA Instruments DSC, Model Q2000 (New Castle, DE) with a refrigerated cooling system. Calibration was done with an empty pan for baseline and with indium for temperature. Samples $(7-8 \mathrm{mg})$ were weighed into Tzero aluminum pans and encapsulated. The sample was equilibrated at $90^{\circ} \mathrm{C}$ for $5 \mathrm{~min}$, cooled down to $-60^{\circ} \mathrm{C}$ at $10^{\circ} \mathrm{C} \mathrm{min}^{-1}$, set at $-60^{\circ} \mathrm{C}$ for $20 \mathrm{~min}$, and then heated to $120^{\circ} \mathrm{C}$ at $10^{\circ} \mathrm{C} \mathrm{min}{ }^{-1}$ under dry nitrogen purged at $50 \mathrm{ml} \mathrm{min}^{-1}$. Data was analyzed using the TA Universal Analysis software. Two analytical replicates were averaged for each sample.

\subsection{Analysis of Oxidation by ${ }^{\top} \mathrm{H}$ NMR Spectroscopy}

The ${ }^{1} \mathrm{H}$ NMR has been known to be a reliable analytical method, especially for oil heated at relatively high temperatures. ${ }^{[28]}$ For oleogel samples heated at $90^{\circ} \mathrm{C}$, the ${ }^{1} \mathrm{H}$ NMR method was used to determine the oxidation status of oleogels along with the FAME analysis. In brief, oleogel samples (about $80 \mu \mathrm{l}$ ) were dissolved in $\mathrm{CDCl}_{3}$ (about $0.6 \mathrm{ml}$ ) and transferred to NMR tubes. ${ }^{1} \mathrm{H}$ NMR spectra were acquired on a Bruker (Billerica, MA) Avance 500 spectrometer operating at $500 \mathrm{MHz}$. SpinWorks 3.1.7 software was used to integrate signals using the triacylglycerol backbone proton signal (four protons, at 4.06$4.36 \mathrm{ppm}$ ) as the standard peak. Losses of olefinic (5.29$5.45 \mathrm{ppm})$ and bisallylic $(2.17-2.85 \mathrm{ppm})$ protons are reported. No analytical replicates were tested because no substantial differences were observed with repeated analyses with one sample as reported previously. ${ }^{[28]}$

\subsection{Color Penetration Experiment}

In an assumption that the diffusion rate of dye through oleogel reflects the diffusion rate of oxygen, a new method was developed in this study. For $3 \%$ wax-fish oil oleogels, wax (1.08g) was weighed into a $100 \mathrm{ml}$ Erlenmeyer flask and fish oil (34.92 g) was added. While argon was blown over the oil, the mixture was heated on a hotplate with swirling from time to time until the wax was dissolved. While argon was blown, the solution was transferred to three NMR tubes $(9.9 \mathrm{~mm}$ O.D. $\times 180 \mathrm{~mm}$ height, Precision NMR Sample Tubes, New Era Enterprises, Inc., 
Vineland, NJ) to the height of $10 \mathrm{~cm}$ from the bottom. Sample tubes were placed in a metal rack to keep them upright, heated in a $90{ }^{\circ} \mathrm{C}$ oven for $15 \mathrm{~min}$. Samples were moved to another metal rack at room temperature to cool down the samples. The same procedure was followed for oleogels with different amounts of wax. Sudan III $(0.09 \mathrm{~g})$ was dissolved in fish oil $(180 \mathrm{~g})$ in a $300 \mathrm{ml}$ beaker with stirring to prepare the $0.05 \%$ Sudan III solution in fish oil. The Sudan III solution was gently added on top of the oleogel sample in the NMR tube to the mark made at $5 \mathrm{~cm}$ higher from the oleogel level. Samples were placed in the metal rack to keep them upright and stored at 35 and $50{ }^{\circ} \mathrm{C}$. In general, the color developed unevenly. Therefore, the maximum and the minimum distances were averaged.

\subsection{Statistics}

All the storage experiments at 35 and $50^{\circ} \mathrm{C}$ and color penetration experiments were carried out in triplicate and in randomized order. PV, CDV, FAME, and DSC analyses were conducted in duplicate. Data were analyzed by one-way analysis of variance (ANOVA) and all means of the oxidation data were compared by Tukey-Kramer HSD test with statistical significance at a " $P$ " value less than or equal to 0.05 .

\section{Results and Discussion}

\subsection{Oxidation of $3 \%$ Wax-Fish Oil Oleogels at $35^{\circ} \mathrm{C}$}

The first goal of this study was to investigate the efficacy of different waxes in protecting fish oil from oxidation. For this purpose, 3\% wax-fish oil oleogels were prepared with four different waxes, rice bran wax (RBW), sunflower wax (SW), candelilla wax (CW), and beeswax (BW) and stored at 35 and $50^{\circ} \mathrm{C}$, which were known to have stronger gelling abilities than other waxes. ${ }^{[5]}$ Figure 1a shows peroxide values (PV) of $3 \% \mathrm{SW}$ fish oil oleogel samples stored at $35^{\circ} \mathrm{C}$ for 0,7 , and 21 days. It is well known that the PV reaches a peak value in a short period of time and, therefore, only values measured before the peak are meaningful for the comparison of different samples. ${ }^{[29]}$ In our study, the PV reached a peak at Day 21 for all the samples at $35^{\circ} \mathrm{C}$ and the most meaningful data were obtained at Day 7. At Day 7, PV's of all the $3 \%$ SW-fish oil oleogel samples were lower than the control indicating that, regardless of the kind of wax, fish oil oxidation was reduced by gelling the oil. In comparison between waxes, BW and CW showed significantly $(P=0.05)$ lower PV's than RBW. The circulation of oil is significantly reduced by gelling compared to bulk oil. Therefore, it is believed that the relatively slower circulation of oil in oleogel led to the slower oxidation of oil in oleogel. Kodali ${ }^{[19]}$ also reported slower increase a)

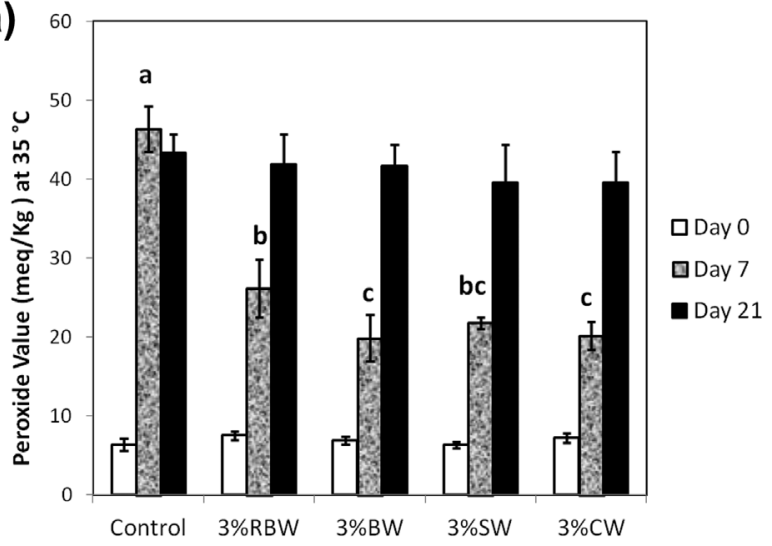

b)

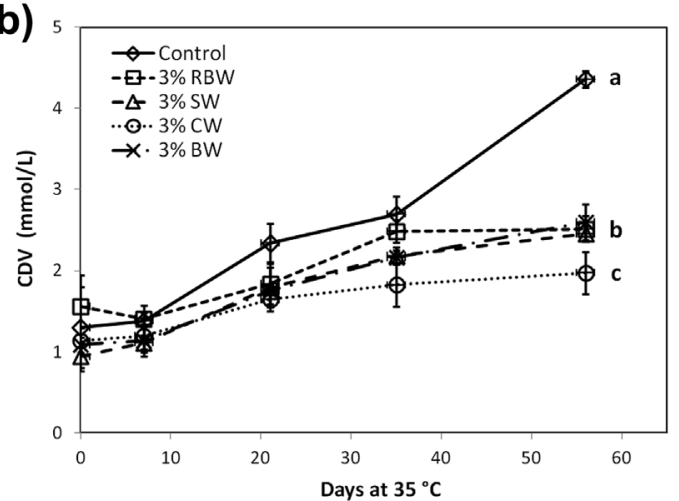

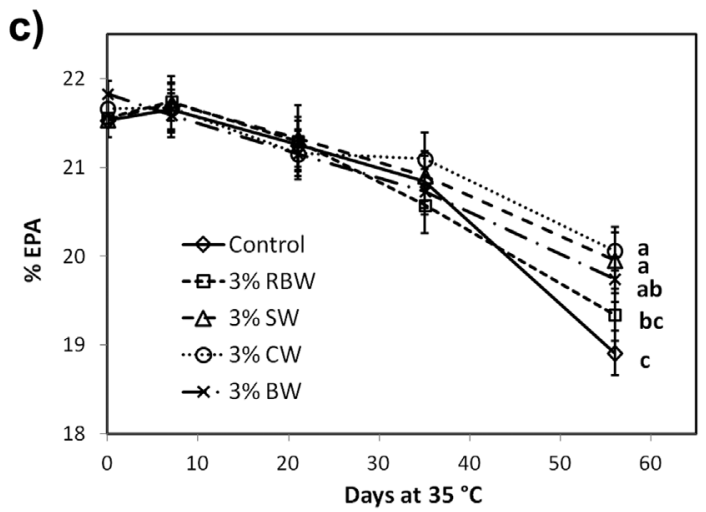

d)

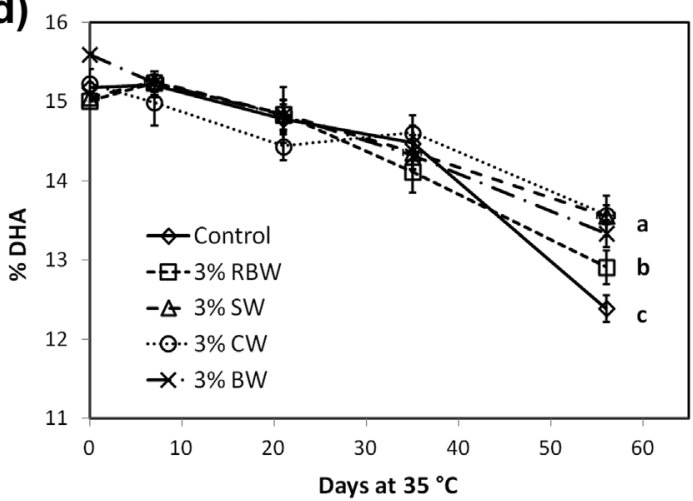

Figure 1. Oxidation of $3 \%$ wax-fish oil organogels at $35^{\circ} \mathrm{C}$ : a) PV up to 21 days, b) $\mathrm{CDV}$ up to 49 days, c) relative concentrations of EPA (20:5) and d) DHA (22:6) up to 56 days. Error bars represent standard deviations. Means not sharing the same letter (s) are significantly different by Tukey-Kramer HSD test $(P<0.05)$. 
in PV with oleogel formed with carnauba wax and RBW. However, Ogutcu, et al. ${ }^{[12]}$ reported contradictory results that CW oleogel showed a higher PV than bulk oil and that BW oleogel gave a similar PV as bulk oil at $20^{\circ} \mathrm{C}$. The reason for different results could be due to the different experimental conditions such as the storage temperature and the ratio of surface area to volume of the sample.

Although the level of oxidation may increase beyond the acceptable level during a long period of storage, the effect by wax will be shown more clearly after a longer storage time. Therefore, for better understanding on effects of different waxes on oxidation of fish oil, we stored 3\% wax-fish oil oleogels for 59 days at $35^{\circ} \mathrm{C}$ and measured the conjugated diene value (CDV), which, in general, reaches a peak value later than PV (Figure 1b). As shown in Figure 1b, the CDV analysis also showed that all four waxes effectively protected fish oil from oxidation. After 56 days, CW showed a better effect than RBW, SW, and BW. Oxidation of oleogel was also determined by the FAME analysis. Among other fatty acids analyzed, two fatty acids, eicosapentaenoic acid (EPA) and docosahexaenoic acid (DHA) are reported in this study (Figure 1c,d). These fatty acids are the most important ones for health benefits and the most affected by the oxidation process. The concentrations of EPA and DHA for all the samples were not significantly different up to 35 days. However, at Day 56, all the oleogel samples showed less oxidation than the control (the bulk fish oil) indicating the effective protection of fish oil by gelling with wax. CW and SW showed the best protection followed by BW and then RBW. Overall, from the four different indications of oxidation, CW was the most effective wax in protection of fish oil from oxidation at $35^{\circ} \mathrm{C}$.

\subsection{Oxidation of $3 \% \mathrm{Wax}-\mathrm{Fish}$ Oil Oleogels at $50^{\circ} \mathrm{C}$}

Peroxide values (PV) of oleogel samples became so random after Day 7 at $50^{\circ} \mathrm{C}$ and only data at Day 3 showed meaningful results (Figure 2a). The most notable result was that BW, which showed the lowest PV at $35^{\circ} \mathrm{C}$, showed no protective effect at $50^{\circ} \mathrm{C}$. Furthermore, unlike the results at $35^{\circ} \mathrm{C}$, RBW showed the best effect. The CDV of oleogels stored at $50^{\circ} \mathrm{C}$ reached the peak value at 35 days and after that, values became so random that no meaningful information was obtained. Therefore, only CDV up to 35 days are reported (Figure 2b). At Day 35, all waxes except for BW showed the obvious protective effect by gelling. CW showed the lowest CDV among waxes. The EPA (Figure 2c) concentration also showed that BW did not give the protective effect and it rather showed faster decreases in concentrations of these fatty acids. DHA analysis showed very similar results as EPA (data not shown). Oleogels made with SW and RBW also showed lower

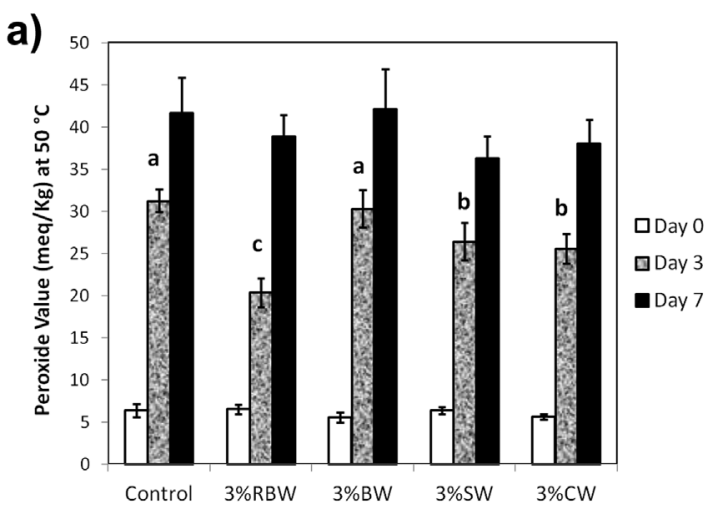

c)

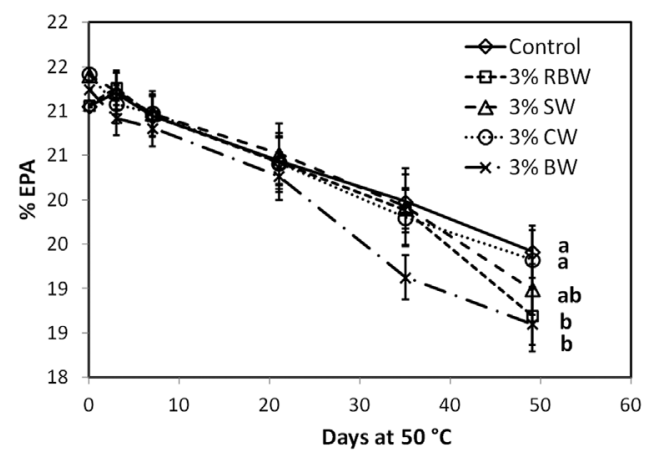

b)
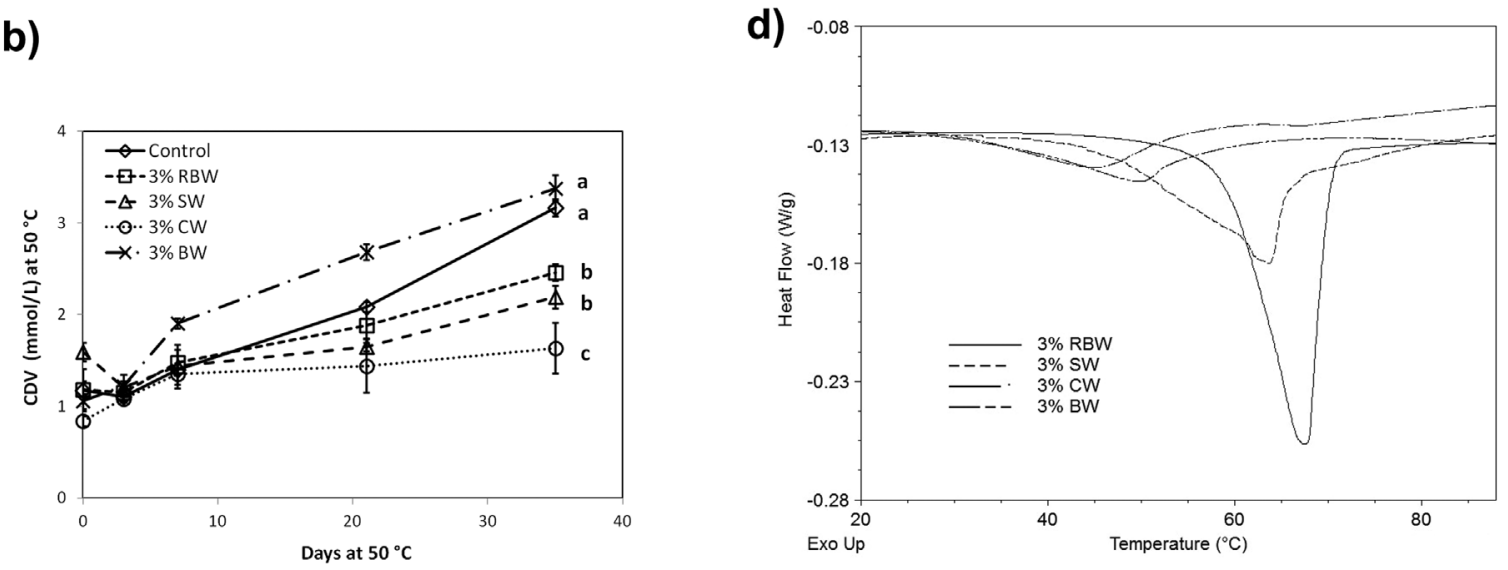

Figure 2. Oxidation of $3 \%$ wax-fish oil organogels at $50^{\circ} \mathrm{C}$ : a) PV on Day 3, b) CDV up to 49 days, c) concentration of EPA (20:5), d) concentration of DHA (22:6), and e) DSC curves of $3 \%$ wax-fish oil oleogels during heating at $10^{\circ} \mathrm{Cmin}^{-1}$. Error bars represent standard deviations. Means not sharing the same letter (s) are significantly different by Tukey-Kramer HSD test $(P<0.05)$. 
concentrations of EPA at Day 49. Therefore, unlike PV and CDV indicating the protective effect by wax, EPA data at Day 49 showed that the waxes might have exhibited the prooxidant activity. Yilmaz et al. ${ }^{[13]}$ also reported higher PV and shorter oxidative induction time (OIT) with a BW-fish oil oleogel than the control (bulk fish oil) indicating the prooxidant activity of BW. Different indications of lipid oxidation often give contradictory results. ${ }^{[21]}$ Therefore, the different results between FAME analysis and PV and CDV analyses in Figure 2a-c can be explained by the difference between the formation of a certain type of oxidation product and disappearance of starting materials. ${ }^{[29]}$

To understand the different trends observed at 35 and $50^{\circ} \mathrm{C}$, DSC experiments were conducted (Figure 2d). The onset melting and the peak melting temperatures for $\mathrm{BW}$ were measured at $34.2 \pm 1.7^{\circ} \mathrm{C}$ and $50.12 \pm 0.4^{\circ} \mathrm{C}$, respectively, indicating that a significant amount of $\mathrm{BW}$ was melted at $50^{\circ} \mathrm{C}$. It is believed that the majority of BW crystals melted and wax crystal networks had been compromised at $50^{\circ} \mathrm{C}$. In contrast, CW having the lowest melting peak $\left(45.5 \pm 0.4^{\circ} \mathrm{C}\right)$ showed significant protective effects for PV and CDV at $50^{\circ} \mathrm{C}$. This can be explained by the small second melting peak at $67.7 \pm 0.1^{\circ} \mathrm{C}$, which might have maintained the gel structure even at $50^{\circ} \mathrm{C}$ and retarded the oil oxidation. More than one DSC peak of $\mathrm{CW}$ is attributed to its various components including $\mathrm{n}$ alkane C29-C33 (49-50\%), esters of higher molecular weight (20-29\%), free acids (7-9\%), and resins (12-14\%, mainly triterpenoid ester. ${ }^{[30]}$ In contrast, 3\% RBW-FO oleogel having the highest melting point showed the lowest PV and relatively low $\mathrm{CDV}$ at $50^{\circ} \mathrm{C}$. Although there would be other factors affecting the protection effect such as wax crystal structures and their networks, the melting point of wax could be one factor that can affect the oxidation of oleogel.

\subsection{Oxidation of $3 \%$ Wax-Fish Oil Oleogels at $90^{\circ} \mathrm{C}$}

To investigate if wax acts as a prooxidant, we conducted another heating study at $90^{\circ} \mathrm{C}$. At $90^{\circ} \mathrm{C}$, all the ingredients of wax were dissolved so that the gelling effect was eliminated. Although some differences in oxidation mechanisms were expected at different temperatures, the heating study at $90^{\circ} \mathrm{C}$ was the best way to investigate the prooxidant activity of wax. PV and CVD were not considered to be good indicators of oil oxidation at $90^{\circ} \mathrm{C}$ since they reach a peak value so quickly. The NMR method ${ }^{[28]}$ is known to be a very reliable method to assess lipid oxidation at relatively high temperatures. Therefore, the NMR method was used to determine oil oxidation in addition to the FAME analysis. Table 1 shows losses of EPA, DHA, olefinic protons, and bisallylic protons of $3 \%$ wax-fish oil oleogels compared to the control (bulk fish oil). EPA and DHA data showed that although some are not statistically significant at $P=0.05$, the general trend was that wax accelerated the oxidation of fish oil. Losses of olefinic and bisallylic protons observed in the NMR spectrum showed the more obvious prooxidant activity of wax. Therefore, it can be concluded that the wax acts as a prooxidant, which should be considered an important factor in the application of the oleogel technology in foods. If the major components of wax such as wax esters and hydrocarbons are not considered as prooxidants from their molecular structures, minor ingredients in $\mathrm{wax}^{[31]}$ may be the major prooxidants in wax.

\subsection{Firmness and Color Penetration Study}

Although oil binding capacity and rheology are widely used to examine physical properties of oleogel, it is inevitable that the crystal network of oleogel is partly or completely broken during these experiments and, consequently, the properties measured with these methods are after the initial crystal network was broken. However, the oxidation of fish oil in oleogel in this study is more closely related to the crystal network and resulting immobilized oil rather than the physical properties after breaking the network. One property that can reflect the density of the network is firmness, the force required by the probe to break the initial crystal network. To understand if firmness correlates with the oxidation rate of fish oil, firmnesses of oleogels were measured (Figure 3a). The result shows that 3\% SW oleogel had greater firmness than the other three oleogels. The trend found in the firmness data did not well correlate with

Table 1. Oxidation of $3 \%$ wax-fish oil oleogels during heating at $90^{\circ} \mathrm{C}$ for 5 and 10 days.

\begin{tabular}{|c|c|c|c|c|c|}
\hline & Control & $3 \% \mathrm{RBW}$ & $3 \% \mathrm{SW}$ & $3 \% \mathrm{BW}$ & $3 \% \mathrm{CW}$ \\
\hline \multicolumn{6}{|l|}{5 days } \\
\hline$\%$ Loss of EPA & $2.18 \pm 0.13^{b}$ & $2.39 \pm 0.88^{b}$ & $3.56 \pm 0.32^{\mathrm{a}}$ & $3.37 \pm 0.30^{\mathrm{a}}$ & $3.41 \pm 0.24^{\mathrm{a}}$ \\
\hline$\%$ Loss of DHA & $12.96 \pm 1.62^{\mathrm{c}}$ & $13.26 \pm 0.72^{c}$ & $16.61 \pm 0.41^{\mathrm{ab}}$ & $17.37 \pm 0.68^{\mathrm{a}}$ & $15.92 \pm 0.37^{b}$ \\
\hline \% Loss of olefinic $\mathrm{H}$ & $3.38 \pm 0.09^{c}$ & $5.02 \pm 0.07^{b}$ & $5.45 \pm 0.18^{b}$ & $5.01 \pm 0.26^{b}$ & $5.71 \pm 0.47^{\mathrm{ab}}$ \\
\hline \% Loss of bisallylic $\mathrm{H}$ & $4.18 \pm 0.09^{\mathrm{b}}$ & $5.79 \pm 0.11^{\mathrm{a}}$ & $6.27 \pm 0.21^{\mathrm{a}}$ & $5.84 \pm 0.22^{\mathrm{a}}$ & $6.04 \pm 0.40^{\mathrm{a}}$ \\
\hline \multicolumn{6}{|l|}{10 days } \\
\hline \% Loss of EPA & $6.54 \pm 0.12^{c}$ & $6.78 \pm 0.33^{b c}$ & $7.66 \pm 0.40^{\mathrm{a}}$ & $7.43 \pm 0.43^{\mathrm{ab}}$ & $6.92 \pm 0.26^{\mathrm{abc}}$ \\
\hline$\%$ Loss of DHA & $19.91 \pm 0.82^{b}$ & $20.07 \pm 0.19^{b}$ & $22.18 \pm 0.31^{\mathrm{a}}$ & $22.28 \pm 0.17^{\mathrm{a}}$ & $21.15 \pm 0.43^{\mathrm{ab}}$ \\
\hline \% Loss of olefinic $\mathrm{H}$ & $6.31 \pm 0.31^{b c}$ & $7.57 \pm 0.32^{\mathrm{a}}$ & $7.95 \pm 0.16^{\mathrm{a}}$ & $7.71 \pm 0.13^{\mathrm{a}}$ & $6.74 \pm 0.30^{b}$ \\
\hline$\%$ Loss of bisallylic $\mathrm{H}$ & $8.87 \pm 0.24^{b}$ & $9.92 \pm 0.40^{\mathrm{a}}$ & $10.17 \pm 0.61^{\mathrm{a}}$ & $10.13 \pm 0.21^{\mathrm{a}}$ & $8.59 \pm 0.25^{b}$ \\
\hline
\end{tabular}

Values not sharing the same letter $(\mathrm{s})$ within each row are significantly different by Tukey-kramer HSD test $(P<0.05)$. 
a)
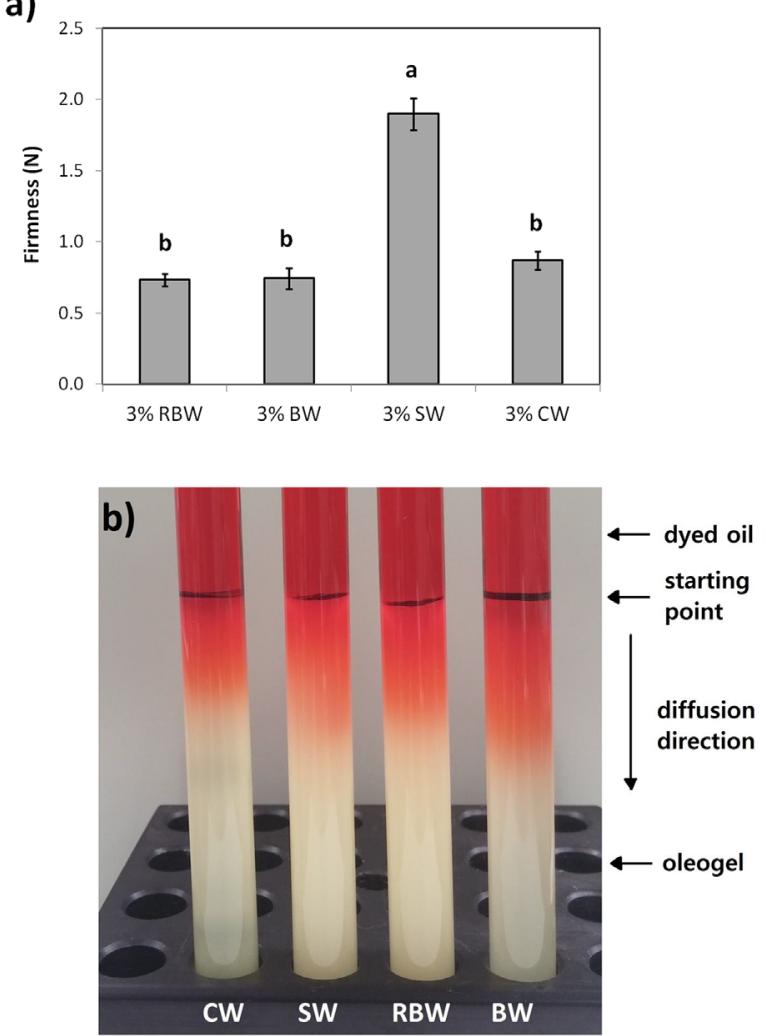

c)

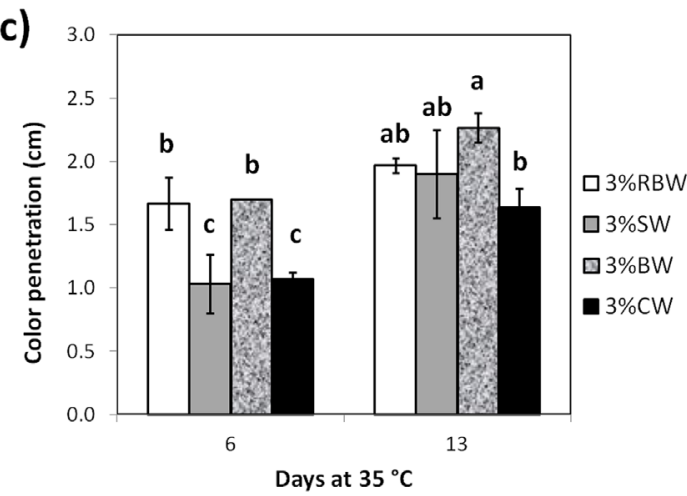

d)

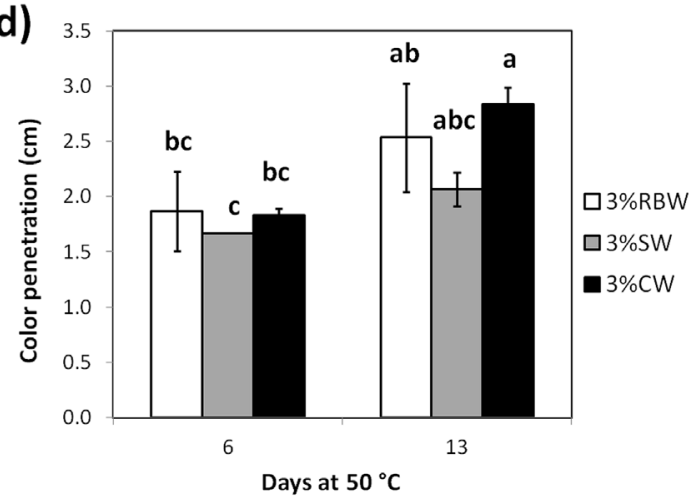

Figure 3. a) Firmness of $3 \%$ wax-fish oil oleogels, b) a representative picture of samples for color penetration experiments, c) color penetration at $35^{\circ} \mathrm{C}$, and d) color penetration at $50^{\circ} \mathrm{C}$. Error bars represent standard deviations. Means not sharing the same letter (s) are significantly different by TukeyKramer HSD test $(P<0.05)$.

markers of oil oxidation. This indicates that SW, having the highest physical strength, does not necessarily have the densest network impeding the diffusion of oxygen into the gel at 35 and $50^{\circ} \mathrm{C}$.

In an attempt to develop a new method that can explain and predict the efficacy of wax on preventing oil oxidation, the color penetration experiment was designed. In this method, it was assumed that the diffusion rate of dye through oleogel can reflect the diffusion rate of oxygen. The color penetration study was conducted at $35^{\circ} \mathrm{C}$ and $50^{\circ} \mathrm{C}$. Figure $3 \mathrm{~b}$ shows the representative picture of samples stored for 13 days at $35^{\circ} \mathrm{C}$. Figure $3 \mathrm{c}$ shows the measurement of the color penetration of four different oleogel samples stored at $35^{\circ} \mathrm{C}$. The slower color penetration for $3 \% \mathrm{CW}$ and SW oleogels at Day 6 well explained the slower oxidation of these oleogels shown in the CDV, EPA, and DHA analyses. Therefore, the color penetration rate correlated with the oxidation rates of oleogels better than the firmness values. Figure $3 \mathrm{~d}$ shows the color penetration rate at $50^{\circ} \mathrm{C}$. At $50{ }^{\circ} \mathrm{C}, 3 \%$ $\mathrm{BW}$ oleogel showed such fast color penetration that the color penetrated all the way to the bottom of the sample in 1 day and so Figure $3 \mathrm{~d}$ does not have the result of BW. The fastest color penetration of $3 \% \mathrm{BW}$ oleogel well correlated with the worst protection of fish oil from oxidation by BW shown in all the analyses; PV, CDV, EPA, and DHA at $50^{\circ} \mathrm{C}$. However, the slowest color penetration observed with $3 \%$ SW oleogel did not provide the best protection of oil oxidation, which may be attributed to the prooxidant activity of SW. As shown in Table 1, it was found that SW had a stronger prooxidant activity than CW and RBW although some values were not statistically significant at $P=0.05$.

\subsection{The Effect of Cooling Rate}

The cooling rate is one very important factor determining oleogel's properties. The faster cooling during the gelling process significantly increases the firmness of oleogel. Our previous study showed that the firmness of $3 \% \mathrm{SW}$-soybean oil oleogel increased by about fourfold with increasing the cooling rate from 1 to $4{ }^{\circ} \mathrm{C} \min ^{-1}$. ${ }^{[5]}$ The faster cooling produces a larger number of smaller wax crystals and provides a denser three dimensional crystal network. ${ }^{[32]}$ Blake and Marangoni ${ }^{[33]}$ also reported that rapid cooling decreased crystal length, decreased network pore area fraction, and increased the fractal dimension of the crystal network resulting in an increase in the oil binding capacity of wax-peanut oil oleogels. To understand the effect of the cooling rate on the efficacy of oleogel in protecting fish oil from oxidation, $3 \% \mathrm{SW}$ oleogels were prepared at three different cooling rates. Figure 4a shows PV of $3 \%$ SW-fish oil oleogels prepared at the cooling rate of $5.3^{\circ} \mathrm{C} \mathrm{min}^{-1}, 11.0^{\circ} \mathrm{C} \mathrm{min}^{-1}$, and $25.3^{\circ} \mathrm{C} \mathrm{min}{ }^{-1}$ and stored at $35^{\circ} \mathrm{C}$. At Day 21, the PV of all three samples reached the peak and did not show statistically 
a)

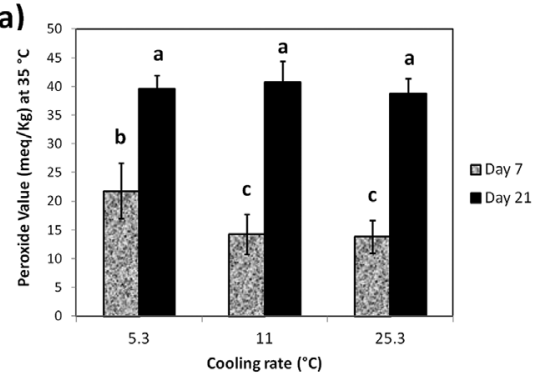

b)

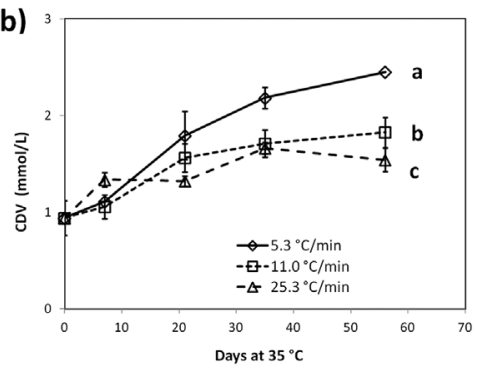

c)

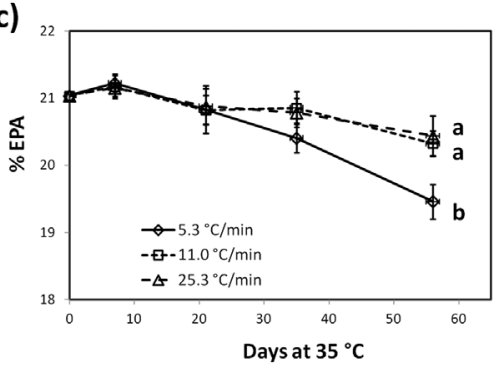

d)

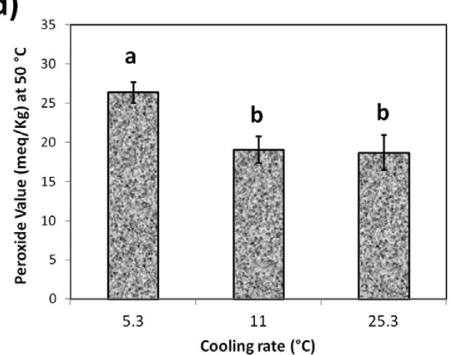

e)

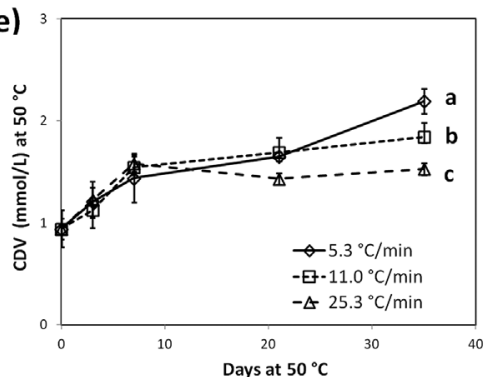

f)

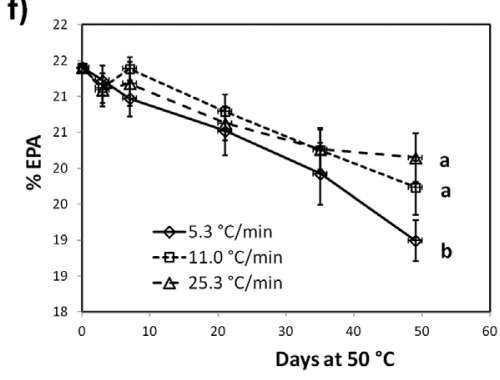

Figure 4. Oxidation of $3 \% \mathrm{SW}$-fish oil organogels prepared at different cooling rates: A) PV, b) $C D V$, and c) $E P A$ at $35^{\circ} \mathrm{C}$ and d) $P V$, e) $C D V$, and f) $E P A$ at $50^{\circ} \mathrm{C}$. Error bars represent standard deviations. Means not sharing the same letter (s) are significantly different by Tukey-Kramer HSD test $(P<0.05)$.

significant differences between oleogels. At Day 7, 3\% SW oleogels prepared at the faster cooling rates, 11.0 and $25.3^{\circ}$ $\mathrm{C} \mathrm{min}^{-1}$, showed the lower PV than the oleogel prepared at the slower cooling rate, $5.3^{\circ} \mathrm{C} \mathrm{min}^{-1}$. Figure $4 \mathrm{~b}$ also showed that the faster cooling rates resulted in lower CDV's. The FAME analysis also showed slower decreases in EPA and DHA with oleogels prepared at cooling rates of 11.0 and $25.3^{\circ} \mathrm{C} \mathrm{min}^{-1}$ than the one prepared at $5.3^{\circ} \mathrm{Cmin}^{-1}$. Figure $4 \mathrm{c}$ shows the change in EPA (DHA showed a very similar trend as EPA). Overall, increasing the cooling rate from $5.3^{\circ} \mathrm{C} \mathrm{min}^{-1}$ to $11.0^{\circ} \mathrm{C} \mathrm{min}^{-1}$ showed the more significant improvement than increasing from 11.0 to $25.3^{\circ} \mathrm{C} \mathrm{min}^{-1}$.

At $50^{\circ} \mathrm{C}$, PV data on Day 3 showed that increasing the cooling rate from $5.3^{\circ} \mathrm{C} \mathrm{min}^{-1}$ to 11.0 and $25 .{ }^{\circ} \mathrm{C} \mathrm{min}^{-1}$ significantly reduced the oxidation of oleogel (Figure $4 \mathrm{~d}$ ). The CDV values also showed that the faster cooling provided better protection of fish oil from oxidation (Figure 4e). The change in concentrations of EPA (Figure 4f) confirmed that the faster cooling rate could provide better protection of oil. Similarly to the results at $35^{\circ} \mathrm{C}$, the improvement observed by increasing the cooling rate from 11.0 to $25.3^{\circ} \mathrm{C} \mathrm{min}^{-1}$ was not as significant as that observed with increasing it from 5.5 to $11.0^{\circ} \mathrm{C} \mathrm{min}^{-1}$.

\subsection{Effect of Wax Amount}

The higher wax concentration provides an oleogel with higher firmness, denser crystal networks, and higher melting point. ${ }^{[3,32]}$ To understand the effect of wax concentration on oil protection, oleogels made with five different concentrations of SW was examined (Figure 5). Figure 5a shows that the amount of SW did not affect the initial PV $\left(4.36,3.95,4.31,4.26\right.$, and $4.47 \mathrm{meq} \mathrm{Kg}^{-1}$ for 1, 3, 5, 7, and 9\% SW oleogels, respectively, at Day 0). After 7 days at $35^{\circ} \mathrm{C}, 5 \% \mathrm{SW}$ showed lower PV than other oleogels, but more wax did not provide better protection of oil. Again, PV values at Day 21 already reached the peak value and did not give meaningful results. The CDV analysis showed that the oxidation of $9 \%$ SW oleogel was faster than 1-7\% SW oleogels as shown in Figure $5 \mathrm{~b}$. The prooxidant activity of SW was more pronounced in the levels of EPA and DHA, which decreased faster with oleogels with higher concentrations of SW. Figure $5 c$ shows the change of EPA. DHA showed a very similar trend as EPA and data are not shown. These results indicate that more SW adversely affected the protection of oil from oxidation due to the prooxidant activity of SW as seen in Table 1 . PV values at Day 7 did not show this prooxidation activity, presumably, due to the too short storage time to show this effect.

At $50^{\circ} \mathrm{C}$, lower PV's were observed with the higher concentrations of SW (5-9\%) than lower SW (1-3\%) on Day 3 while the concentration beyond $5 \%$ did not further improve the protecting effect (Figure $5 \mathrm{~d}$ ). No meaningful data were obtained at Day 7 since all the PV's passed over the peak value (data not shown). CDV showed that 3-9\% SW protected fish oil from oxidation better that $1 \% \mathrm{SW}$ (Figure 5e). CDV's of 3-9\% SW oleogels were lower than that of $1 \% \mathrm{SW}$ oleogel during the storage period of Day 7 to Day 21 and became similar at Day 35. Therefore, it was concluded that about 3-5\% SW was the most optimized concentration to prevent oil oxidation up to 21 days at $50^{\circ} \mathrm{C}$. EPA concentration up to 35 days did not show significant differences between oleogels (Figure 5f). However, 9\% SW showed faster oxidation than 1-7\% SW indicating the prooxidant activity of SW. Therefore, the more wax in the oleogel does not necessarily provide better protection of fish oil from oxidation.

To further understand the effect of the SW concentration, the color penetration experiments were conducted at 35 and $50{ }^{\circ} \mathrm{C}$ (Table 2). In contrast to the result at $35^{\circ} \mathrm{C}$ that showed no significant differences, the color penetration rate at $50^{\circ} \mathrm{C}$ was significantly decreased with a higher concentration of SW. This 
a)
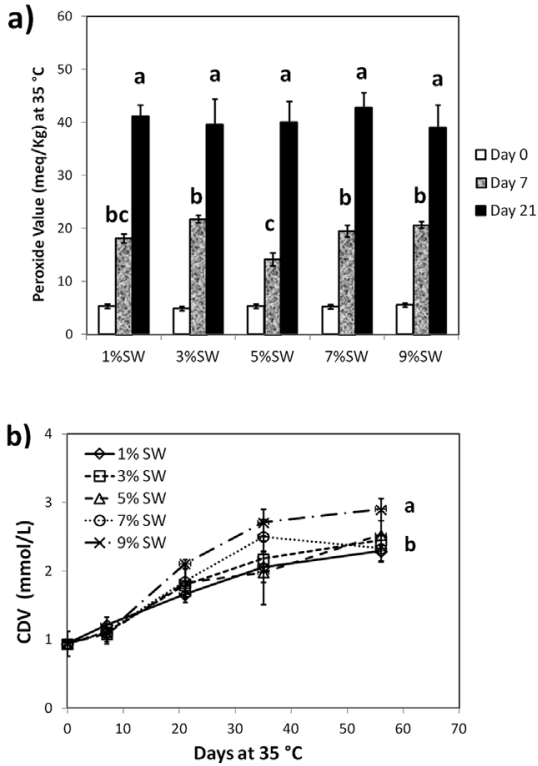

c)
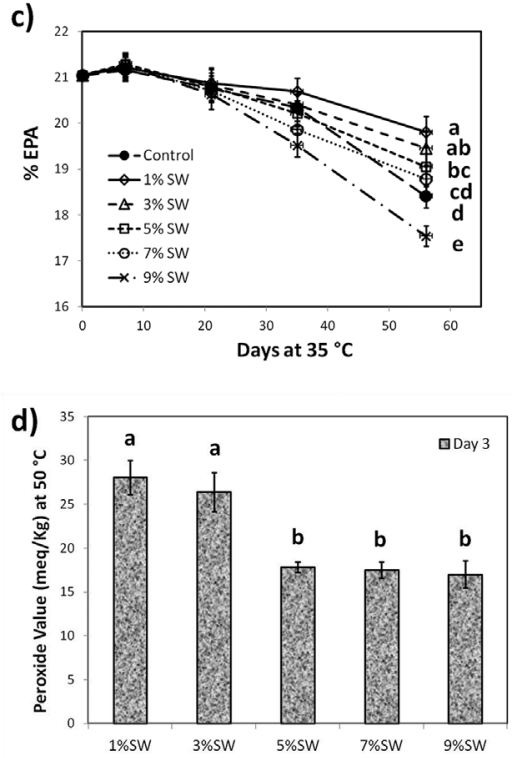

e)

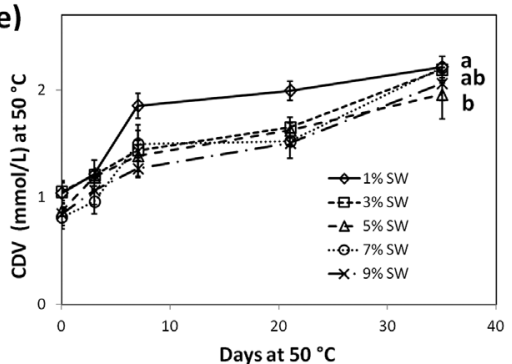

f)

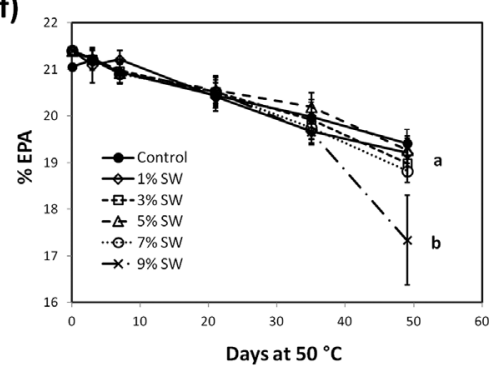

Figure 5. Oxidation of fish oil organogels containing 1, 3, 5, 7, and $9 \% \mathrm{SW}$ : a) $\mathrm{PV}, \mathrm{b}) \mathrm{CDV}$, and c) $\mathrm{EPA}$ at $35^{\circ} \mathrm{C}$ and d) $\mathrm{PV}$, e) $\mathrm{CDV}$, and f) $\mathrm{EPA}$ at $50^{\circ} \mathrm{C}$. Error bars represent standard deviations. Means not sharing the same letter (s) are significantly different by Tukey-Kramer HSD test $(P<0.05)$.

Table 2. Color penetration (cm), loss of EPA (\%), and loss of olefinic protons (\%) of 1-9\% SW-fish oil oleogels.

\begin{tabular}{|c|c|c|c|c|c|}
\hline & $1 \% \mathrm{SW}$ & $3 \% \mathrm{SW}$ & $5 \% \mathrm{SW}$ & $7 \% \mathrm{SW}$ & $9 \% \mathrm{SW}$ \\
\hline Color penetration, $35^{\circ} \mathrm{C}$, Day 6 & $1.13 \pm 0.06^{\mathrm{a}}$ & $1.03 \pm 0.23^{\mathrm{a}}$ & $1.37 \pm 0.50^{\mathrm{a}}$ & $1.17 \pm 0.15^{\mathrm{a}}$ & $1.33 \pm 0.32^{\mathrm{a}}$ \\
\hline Color penetration, $35^{\circ} \mathrm{C}$, Day 13 & $1.63 \pm 0.06^{\mathrm{a}}$ & $1.90 \pm 0.35^{\mathrm{a}}$ & $1.47 \pm 0.50^{\mathrm{a}}$ & $1.43 \pm 0.06^{\mathrm{a}}$ & $1.47 \pm 0.47^{\mathrm{a}}$ \\
\hline Color penetration, $50^{\circ} \mathrm{C}$, Day 6 & $1.80 \pm 0.06^{\mathrm{ab}}$ & $1.67 \pm 0.00^{\mathrm{abc}}$ & $1.63 \pm 0.00^{\mathrm{bcd}}$ & $1.30 \pm 0.10^{\text {cde }}$ & $0.97 \pm 0.12^{\mathrm{e}}$ \\
\hline Color penetration, $50^{\circ} \mathrm{C}$, Day 13 & $2.67 \pm 0.06^{\mathrm{a}}$ & $2.07 \pm 0.15^{b}$ & $2.07 \pm 0.25^{\mathrm{b}}$ & $1.60 \pm 0.15^{\text {cde }}$ & $1.23 \pm 0.15^{\mathrm{ef}}$ \\
\hline Loss of EPA, $90^{\circ} \mathrm{C}$, Day 5 & $2.23 \pm 0.74^{\mathrm{b}}$ & $3.56 \pm 0.32^{\mathrm{a}}$ & $3.47 \pm 0.27^{\mathrm{a}}$ & $3.70 \pm 0.30^{\mathrm{a}}$ & $3.48 \pm 0.21^{\mathrm{a}}$ \\
\hline Loss of EPA, $90^{\circ} \mathrm{C}$, Day 10 & $7.21 \pm 0.51^{\mathrm{a}}$ & $7.66 \pm 0.40^{\mathrm{a}}$ & $7.48 \pm 0.74^{\mathrm{a}}$ & $7.78 \pm 0.34^{\mathrm{a}}$ & $7.77 \pm 0.30^{\mathrm{a}}$ \\
\hline Loss of olefinic protons, $90^{\circ} \mathrm{C}$, Day 5 & $4.71 \pm 0.40^{\mathrm{d}}$ & $5.45 \pm 0.18^{d}$ & $6.56 \pm 0.44^{c}$ & $7.18 \pm 0.55^{b c}$ & $8.90 \pm 0.07^{\mathrm{a}}$ \\
\hline Loss of olefinic protons, $90^{\circ} \mathrm{C}$, Day 10 & $7.57 \pm 0.43^{\mathrm{de}}$ & $7.95 \pm 0.16^{\mathrm{d}}$ & $8.92 \pm 0.14^{c}$ & $10.51 \pm 0.16^{\mathrm{b}}$ & $11.50 \pm 0.33^{a}$ \\
\hline
\end{tabular}

Means not sharing the same letter (s) in each row are significantly different by Tukey-Kramer HSD test $(P<0.05)$.

indicates that while $1 \% \mathrm{SW}$ was good enough for a dense network to prevent oil diffusion at $35^{\circ} \mathrm{C}$, the higher $\mathrm{SW}$ concentration provided the denser crystal networks to more effectively reduce the oil diffusion at $50^{\circ} \mathrm{C}$.

To investigate if more wax caused the more serious prooxidant activity, the heating study at $90{ }^{\circ} \mathrm{C}$ was conducted (Table 2). Again, the gelling effect on oil oxidation was eliminated since all wax crystals melted at $90^{\circ} \mathrm{C}$ and, therefore, only the effect of molten SW was shown in this experiment. 3-9\% SW oleogels showed faster loss of EPA than $1 \%$ SW oleogel at Day 5 indicating the possible prooxidant activity of SW. The olefinic proton signal in NMR showed a clearer prooxidant activity of SW. The greater loss of olefinic protons was observed with a higher concentration of SW. The DHA data and bisallylic proton data were almost identical as EPA and olefinic proton, respectively, and so these data are not presented. This result indicates that the prooxidant activity of wax should be considered in order to understand the oxidation of oleogels in addition to crystal networks that decrease the diffusion rate of oxygen through oleogels.

\section{Conclusions}

It is concluded that the oleogel technology can be used as a method to prevent oil oxidation by immobilizing oil. For the most effectiveness, the amount and kind of oleogelator should be carefully chosen. In this study, it was found that BW did not perform as effectively as other waxes at $50^{\circ} \mathrm{C}$ due to its low melting point. Candelilla wax $(\mathrm{CW})$ having two melting peaks in DSC showed a better protective effect than BW at $50^{\circ} \mathrm{C}$ although the major melting peak of $\mathrm{CW}$ appeared at a lower 
temperature than the melting peak of BW. All the waxes used in this study exhibited a prooxidant activity to a certain extent. Therefore, the prooxidant activity of wax should be considered an important factor in the application of the oleogel technology. The color penetration measurement that was newly developed in this study can be a good, convenient method to predict the effectiveness of oleogels in prevention of oil oxidation although it alone cannot give complete information on the oxidation of oleogel.

\section{Acknowledgements}

The authors would like to express appreciation to Lynne Copes, Julie Anderson, and Ashley Wayman for excellent technical work. Mention of trade names or commercial products in this article is solely for the purpose of providing scientific information and does not imply recommendation or endorsement by the U.S. Department of Agriculture. USDA is an equal opportunity provider and employer.

\section{Conflict of Interest}

The authors declare no conflict of interest.

\section{Keywords}

fish oil, oleogel, omega-3 oil, organogel, oxidation

Received: August 31, 2017

Revised: January 10, 2018

Published online: March 30, 2018

[1] J. Salmerón, F. B. Hu, J. E. Manson, M. J. Stampfer, G. A. Colditz, E. B. Rimm, W. C. Willett, Am. J. Clin. Nutr. 2001, 73, 1019.

[2] V. Chajès, A. C. M. Thiébaut, M. Rotival, E. Gauthier, V. Maillard, M.C. Boutron-Ruault, V. Joulin, G. M. Lenoir, F. Clavel-Chapelon, Am.J. Epidemiol. 2008, 167, 1312.

[3] A. Bysted, A. Æ. Mikkelsen, T. Leth, Eur. J. Lipid Sci. Technol. 2009, 111,574

[4] P. W. Siri-Tarino, Q. Sun, F. B. Hu, R. M. Krauss, Am. J. Clin. Nutr. 2010, 91, 535.

[5] H.-S. Hwang, S. Kim, M. Singh, J. Winkler-Moser, S. Liu, J. Am. Oil Chem. Soc. 2012, 89, 639.
[6] H. S. Hwang, M. Singh, J. K. Winkler-Moser, E. L. Bakota, S. X. Liu, J. Food Sci. 2014, 79, C1926.

[7] A. M. Minihane, D. L. Givens, R. A. Gibbs, Health Benefits of Organic Food: Effects of the Environment, I. Givens, S. Baxter, A. M. Minihane, E. Shaw (Eds.), CAB International, Oxfordshire (England) 2008, pp. 19.

[8] K. S. Sidhu, Regul. Toxicol. Pharmacol. 2003, 38, 336

[9] J. W. Finley, F. Shahidi, ACS Symp. Ser. 2001, 788, 2.

[10] B. Ganesan, C. Brothersen, D. J. McMahon, Crit. Rev. Food Sci. Nutr. 2014, 54, 98.

[11] C. Jacobsen, Ann. N. Y. Acad. Sci. 2010, 1190, 141.

[12] M. Ögütcü, N. Arifoğlu, E. Yilmaz, Int.J. Food Sci. Tech. 2015, 50, 404.

[13] E. Yılmaz, M. Ögütcü, N. Arifoğlu, J. Oleo Sci. 2015, 64, 1049.

[14] M. Öğütcü, R. Temizkan, N. Arifoğlu, E. Yılmaz, J. Oleo Sci. 2015, 64, 713.

[15] E. N. Frankel, Prog. Lipid Res. 1980, 19, 1.

[16] E. N. Frankel, Lipid Res. 1983, 22, 1.

[17] E. N. Frankel, Chem. Phys. Lipids 1987, 44, 73.

[18] S. Da Pieve, S. Calligaris, A. Panozzo, G. Arrighetti, M. C. Nicoli, Food Res. Int. 2011, 44, 2978.

[19] D. R. Kodali, Lipid Technol. 2009, 21, 254.

[20] M. Ögütcü, N. Arifoğlu, E. Yılmaz, J. Am. Oil Chem. Soc. 2015, 92, 459.

[21] J. I. Gray, J. Am. Oil Chem. Soc. 1978, 55, 539.

[22] A. Kamal-Eldin, J. Pokorn, Analysis of Lipid Oxidation, A. Kamal-Eldin, J. Pokorny (Eds.), AOCS Publishing, Champaign (Illinois) 2005, pp. 1.

[23] M. C. Shantha, E. A. Decker, J. AOAC Int. 1994, 77, 421.

[24] AOCS, Spectrophotometric determination of conjugated dienoic acid. In: Official Methods and Recommended Practices of the American Oil Chemists' Society, American Oil Chemists' Society, Champaign (Illinois) 1990. AOCS Official Method Ti 1a-64.

[25] B. A. Brice, M. L. Swain, J. Opt. Soc. Am. 1945, 35, 532.

[26] K. I. Ichihara, A. Shibahara, K. Yamamoto, T. Nakayama, Lipids 1996, 31, 535.

[27] E. L. Bakota, J. K. Winkler-Moser, M. A. Berhow, D. E. Palmquist, S. X. Liu, J. Am. Oil Chem. Soc. 2015, 92, 1333.

[28] H.-S. Hwang, J. K. Winkler-Moser, S. X. Liu, J. Am. Oil Chem. Soc. 2017, 94, 257.

[29] M. Pignitter, V. Somoza, J. Food Drug Anal. 2012, 20, 772.

[30] J. F. Toro-Vazquez, J. A. Morales-Rueda, E. Dibildox-Alvarado, M. Charó-Alonso, M. Alonzo-Macias, M. M. González-Chávez, J. Am. Oil Chem. Soc. 2007, 84, 989.

[31] T. Waraho, D. J. McClements, E. A. Decker, Food Chem. 2011, 129, 854.

[32] H. S. Hwang, S. Kim, K. O. Evans, C. Koga, Y. Lee, Food Struct. 2015, $5,10$.

[33] A. I. Blake, A. G. Marangoni, Food Biophys. 2015, 10, 456. 